\title{
The Second Mouse Gets the Cheese- A Fresh Look at How to Improve Performance at Work through Effective Trust Building
}

\author{
Pavlína Rupová and Dominika Bittnerová
}

Faculty of Psychology, Univerzita Palackeho, Olomouc, Czech Republic

Eddie Fisher (Corresponding author)

Faculty of Social Sciences, Universidad de Oriente, Santiago de Cuba, Cuba

8 Kendal, Swindon, Wiltshire, SN5 8HW, United Kingdom

Tel: 44-179-349-0423 E-mail: eddie.fisher9@ btinternet.com

Received: January 4, 2015 Accepted: January 21, 2015

doi:10.5296/ber.v5i1.6840 URL: http://dx.doi.org/10.5296/ber.v5i1.6840

\begin{abstract}
Managers across the world are under increasing pressures to improve the productivity levels of their teams in line with challenging organizational objectives and goals. This research investigates the value of building trust and how managers can apply this new knowledge practically and effectively in a number of different team structure situations. Outcomes from a literature review, face to face meetings and a focus group are presented, analysed and evaluated to complete the research objectives. A new trust model with specific behaviors and competences associated with effective building trust is presented. The findings suggest that managers need to be passionate about the work and the people they work with, that they must focus their attention on putting others first and that they must create environments based on openness, honesty, leading by example and making others feel special. The new trust model can be applied universally but different corporate and local cultures need to be considered.
\end{abstract}

Keywords: Trust, Attitude, Behavior, Silent Language, Levels of Trust

\section{Introduction}

\subsection{Introduction}

"It is more shameful to distrust our friends than to be deceived by them." Confucius 
"The best way to find out if you can trust somebody is to trust them." Ernest Hemingway

"You cannot be reasonable with those who have no purpose for doing anything. But you can use trust to remove distrust to build viable relationships" Eddie Fisher

It appears that the ability to manage and lead people at work has become a major concern of companies and organizations across the world. They have begun to realize that it is not sufficient to make statements such as 'Our people are our greatest asset'. It is of paramount importance that actions follow such words. Developing managers' abilities to motivate others and take them to new performance levels is now considered to be high priority. This is driven by constantly changing competitive working environments. This places an increasing demand on managers to produce more in less time with fewer people and reduce overhead costs so that products and services can be offered at much lower prices to customers. Customers expect higher levels of quality and this puts even more pressure on managers to deliver products and services that at least meet but preferably exceed these customer expectations. As a direct result, managers need to find new ways of motivating their staff and developing much stronger rapport with them if they wish to succeed in the new working environments. The researchers consider that building trust is a skill that managers need to develop to strengthen their position at work to achieve the desired improvements together with their teams. The primary focus and main purpose of this research is to take a fresh look at building trust and how the adoption of this skill can help managers to become better at managing their teams more effectively. This includes how deaf people build trust applying, for example, the use of the so-called silent language or sign language. This is an important aspect of this research in recognition of the fact that not enough has been done in the past to raise the profile of this underrepresented and yet important minority within society. It should be noted that cultural differences need to be taken into consideration as not all managing people skills such as building trust can be equally applied in any country. What works effectively in one country may not automatically work equally effectively in another country. O'Connor and Lages (2007) suggest that the word trust comes from an Old Norse word meaning 'support'. Someone people trust is someone who people know will support them. They have perhaps demonstrated that they are willing and able to do so. Trust is not a thing but is it a process or relationship, something that is renewed or strengthened every time people meet. Machiavelli (CMI, 2013; 1469-1527) defines trust as having confidence in the honesty, integrity and morality of another person, firmly believing that they will act in accordance with what they say. Trust has many aspects such as being trusted to maintain a confidence, having trusted abilities, being trusted to share the same aims, displaying judgments that people trust, being trusted to give honest feedback, having trustworthy motives and ambitions and being trusted to deliver what the leader wants on time.

The Romans used the Latin word fides which means not only trust but also confidence, reliance, belief and faith. For example, the Latin 'Credo ut intelligam' means 'I believe so that I can understand'. Another example is 'Cras credemus, hodie nihil' which means'Tomorrow we will believe, but not today'. It appears that the Romans suggest that one should take time to think/believe first before trusting someone. In the context of this research, the researchers consider the following definitions of what trust is: 
1. To hand over something physical such as car keys/car to another person and expect them to look after it like it were their own

2. To appeal to someone's integrity when sharing personal or confidential information with them such as health details

3. To expect someone to keep promises they made such as paying back borrowed money by a certain time

4. To make judgments about a person that lead to unconditional acceptance of that person and who they are/what they stand for, for example, in conflict situations where someone will cover the other person in life and death situations

5. To judge someone at the spur of the moment, based on the attitude/behavior, body language and/or intonation of voice, whether to place one's life into the hands of the other person(s), for example, after a car accident

6. To accept another person for what they are and to learn to let go and not control everything

A literature review is presented next, followed by the main research questions and the knowledge gap from the literature review. This forms the theoretical framework of this research and is followed by a presentation of the outputs from face to face interviews and a focus group meeting with six students of social psychology (some of these left University a year ago and were in work placement at the time of the interviews, enhancing the research data by providing useful practical insights) to try and close the knowledge gap considered in section 1.3. The research methodology is presented next. This is followed by the research results and the discussion of what the research found. This is concluded in the final section which includes this research's limitations and suggestions for future research.

\subsection{Literature Review}

\subsubsection{Trust}

Human beings develop their ability to build trust from an early age. Qing Gong et al. (2014) conducted some research and report that the ability of 3- to 5-year-old children to reason about trust in relation to the honest behavior of others was examined across five studies. Results suggest that although 4-year-olds differentiated between honest and dishonest sources in their trust judgments, only 5-year-olds demonstrated a clear capacity to differentiate between honesty and a trust-irrelevant dimension (for example, cleanliness) in these trust judgments. This was seen in their tendency to trust honest characters more than clean ones and to distrust dishonest characters more than unclean ones.

This was also seen in their tendency to choose honest unclean characters over dishonest clean ones in their trust judgments. Results suggest that children use honesty as a basis for selective trust even before they appreciate which specific traits are relevant to trust. A central challenge that children face in learning from others is to know when to accept valid information from others and when to reject information that is incorrect or designed to mislead. Children who incorrectly reject valid information can miss out on valuable learning opportunities, and those who incorrectly accept incorrect or misleading information risk being misinformed or manipulated. Focusing on the adult and business world, Rousseau et al. (1998) developed a 
multi-disciplinary view of trust within and between companies. This study was enriched by drawing on the diverse scholarly contributions of other authors. Rousseau et al. suggest that confident expectations and a willingness to be vulnerable, as proposed by a number of articles within their study, are critical components of all definitions of trust. Based on a collection of cross-disciplinary research papers, they consider that a widely held definition of trust is: 'Trust is a psychological state comprising the intention to accept vulnerability based upon positive expectations of the intentions or behaviors of another' (page 395). They report that it appears that there is agreement on what must be in place before trust can develop. There appears to be a connection between, for example, risk and trust that stems from a reciprocal relationship between the two. Risk creates opportunities for building trust and trust provides opportunities to take risks. Another condition that must be in place is interdependence. People rely on others to achieve their interests and vice versa. Rousseau et al. quote Sheppard and Sherman (1998) who argue that the nature of trust and risk changes in line with increases in interdependence between people. The level of interdependence alters the form trust may take. This has a direct impact on how companies, for example, place trust in their employees. This level of trust differs distinctly depending on whether employees are long serving members or short term contract staff. Rousseau et al. suggest that social psychologists view trust as an either/or: someone either trust another person completely or they do not trust them at all, quoting Gabarro (1990). Rousseau et al. report that social psychologists developed this all or nothing view based on research outcomes that were based on highly structured games such as the Prisoner's Dilemma game. This particular game is highly stylized and demonstrates that sometimes common sense works better than theory and that without common sense even the smallest problems have no formal solution. The game shows how two rational individuals might not co-operate even if this is in their best interests to do so. Pursuing individual rewards rather than co-operating with each other based on trust leads to negative outcomes for both. It proves the point that, under such conditions as this game, the level of trust reflects a single point rather than an intra-or interpersonal continuum (Rousseau et al.). High levels of trust can develop when experiences such as in this game, are repeated and thus tend to result in decisions to co-operate. As such, trust can be conceptualised as an independent variable. They conclude that 'trust takes different forms in different relationships-from a calculated weighing of perceived gains and losses to an emotional response based on interpersonal attachment and identification' (page 398).

Sprenger (2004) suggests that there are some inherent difficulties in trusting people but also considers that the advantages of a culture of trust outweigh the disadvantages. Trust is safer than any safety measure. Trust is more effective control than any control system. Trust creates more value than any value-creation initiative. Trust forms the basis for effective co-operations between people. Sprenger reports that not much has happened since Fox's (1974) proclamation that a culture of high trust provides a competitive advantage. Trust is fascinating. It is linked to many aspects of commercial life such as agreement, reciprocity, co-operation, contracts, management, speed, innovation, reliability and commitment. Sprenger suggests that trust is one of the main management tools in a company, alongside power and money. The need for trust has increased dramatically. This is due to the development of globalized fast markets, flexible working patterns and virtual forms of organizations. Business conditions have changed. 
In the past, people held the view that all circumstances of life will remain constant. This appeared to be the commonly adapted view of trust. Today, trust is considered to be the core of the modern economy. It will become the dominant management theme in the decades to come. Managers need to understand the value of trust in relation to corporate and economic objectives. Trust needs to be prevalent at all levels within organizations, otherwise companies will fail. Hunsaker and Alessandra (2008) assert similar views. They claim that the art of managing people is perhaps the most challenging task facing any manager in today's and tomorrow's constantly changing and demanding work environments. Workplaces have become diverse and complex. Some managerial concepts from the past no longer apply in the new environments. People, business and Government have changed. Attracting, training, motivating and keeping employees have become much more difficult and much more expensive. Mangers have the enviable task to create stronger and longer lasting interpersonal relationships that are based on building trust. Hunsaker and Alessandra suggest that people perform more effectively and productively when managers encourage optimum personality expression at work. When managers empower others so they can decide independently how to perform their own jobs and to express their opinions about how to improve them, then personal, professional and organizational productivity are optimised. Research on human behavior suggests that healthy individuals need to be treated with respect and to have opportunities to feel competent and independent as they actively pursue goals to which they are committed. It appears that all verbal and non verbal behaviors project trust, confidence, patience, empathy and helpfulness. The result of this new form of management is a close, open and trusting manager who has developed win-win relationships with team members.

Jones et al. (2007) purport that trust is an essential ingredient for building, for example, high performance teams. Tasks might drive the team but relationships are of paramount importance to ensure that creativity, quality and customer satisfactions are achieved. Jones considers that for a team to be 'high performing', there needs to be trust, understanding of each other's roles and personalities, openness and mutual respect. Managers need to understand that this does not happen by itself. High-performing teams need to be given the freedom to work on these issues in a planned way so they can develop and grow. In return, team members will be more likely to work with each other, resolve conflicts, support each other and make that extra effort. The three main areas which can help in the process of building relationships are: building trust, open and genuine feedback and review and managing conflict constructively. Managers need to encourage and direct team members to share something about who they are, what they do, how they like to work and what they would like to get out of this team. How people like to work is of particular importance for cross-cultural groups.

For example, some cultures prefer to discuss and agree what to do and other cultures prefer to be told what to do. Honey $(2001 ; 1997 ; 1988)$ suggests that openness is a value that appears to penetrate all the behavioral sciences. This is based on an assumption that if people treat others as they would wish to be treated, then is highly likely that they will respond in kind. Being open and honest with people tends to lead to people reciprocating be being more open themselves People do not have access to thoughts, feelings and motives. They can only observe someone's behavior-their action. Being open and honest about what people think, how they feel and why 
they are doing what they are doing, seems to be efficient and helpful to avoid people wasting their time and energy guessing what the other person is up to. Unless people are open and honest, others are obliged to indulge in speculation.

Piccinini (2013) considers that trust is built over time by consistently exhibiting a number of behaviors and values. Piccinini refers to these as the pillars of trust. People need to say what they mean and mean what they say. Sincerity is of paramount importance. People need to be open and honest with themselves and in their encounters with others. These are known as internal and external congruence. Walking the talk is an important ingredient of trust. Saying one thing but doing something else does not generate any level of trust in others. Managers, for example, should not make any promises they cannot keep. Reliability is another valuable ingredient of trust. People need to be accountable and demonstrate that they are. Managers need to own up to their own mistakes. They need to engage others in the resolution process. This develops strong levels of trust.

Robbins and Finley (1995) suggest that trust is the blood of teams-the river that carries it along, that pulses with life and that brings thought and power to everything the team attempts. Managers should reflect regularly on what they do and should do in order to create and sustain trust. Covey (2004-2006) reports that high trust leaders display certain behaviors than be associated with trustful individuals. They have strong personal credibility, have the ability to create and grow trust with others interpersonally and are then able to extend that trust organizationally. High trust leaders are managers of choice. They understand the impact trust always plays on two key outcomes- speed and cost, and how low or how high trust either extracts a tax or produces a dividend on every activity and dimension within a relationship, team, or organization. Managers with high levels of trust have learned how to interact with others in ways that increases mutual levels of trust rather than depletes them.

Robbins (2002) asserts that when one person trusts another person, they assume that the other person acts honestly and truthfully and that they are reliable and predictable. People also assume that others do not take advantage of the given trust. Trust is the essence of leadership because it is impossible to lead people who do not trust the leader. Employees who trust the leader are willing to be vulnerable to the leader's actions. They are confident that their rights and interests will not be abused by the trusted leader. People who feel that someone is dishonest or who is likely to take advantage of them, are unlikely to follow that person or to look up to them. It appears that honesty ranks highly in the list of characteristics people consider makes a good leader. Robbins suggests that change and instability are omnipotent in today's businesses. This is why many employees now turn to personal relationships for guidance. It is the quality of these relationships that is determined by how much people trust each other. Some contemporary management work practices such as empowering people and virtual teams largely depend on trust between individuals to be effective. Robbins considers a number of approaches managers need to apply if they wish to build good rapport and long-lasting work relationships with their team members. Managers need to be open, keep people informed, explain their rationale for making decisions and be candid about problems. They need to be fair in terms of objectivity and need to reflect this, for example in performance-related pay reviews. The sharing of genuine and authentic feelings will ensure that people see managers as real and 
human. Managers need to tell the truth if they wish to develop long-term trusting relationships with people. People rather hear something they do not really want to hear than finding out that the manager did not tell the truth. People want predictability. Managers need to let their values and beliefs guide their actions. This increases consistency and builds trust. They need to keep their word and promised made. Trust requires that people believe that managers are dependable. People favour managers who are discreet and upon whom they can rely. Managers must not divulge confidential personal information as this will affect the level of trust with others adversely.

Davison and Ward (1999) report that building trust in international teams is a difficult and rewarding task for those who lead and mange others and wish to establish an effective global team. Managers need to understand that trust and interpersonal relationships are built in different ways in different cultures. For example, British and Americans may rush off to complete a task, whereas Latin and Middle Eastern team members may stay unmoved because proper introductions have not been completed yet. Trust is best established at the same time and in the same place. It is much harder across a distance. The use of humor is considered to be an effective ingredient in people management, team building and the building of trusting relationships. It is essential that managers consider the context in which humor is applied. It can have devastating effects if applied inappropriately and inconsiderably. For example, British exclamation marks (!) are often used to show that someone is not serious about a certain subject matter. The opposite is true to say about other cultures. They tend to perceive and interpret these types of exclamation marks to be arrogant, conceited, manipulative and totally insensitive. It is imperative that managers are aware of these differences and that they show considerations for the feelings and cultural differences of others. Trust is built in different ways in different cultures. Irish people make fun and laugh about themselves, the British feel safe if they can understand each other's jokes and aspiring American Presidents tend to deride their weaknesses in the last stages of a campaign. In contrast, most Germans view the idea of establishing trust after only a few meetings as meaningless. They want to see the steadiness and quality of the work first before venturing into building trust in earnest.

According to Blanchard et al. (2013) the ability to build trust is the defining competency for leaders in the $21^{\text {st }}$ century. Some companies have taken proactive steps to build high-trust cultures. They have experienced that high levels of trust within their organizations have led to positive improvements of their bottom line. Some by-products of trust are flourishing creativity, rising levels of productivity, overcoming barriers and deepening of relationships. Blanchard et al. suggest that building trust is of particular importance to those who lead or manage others. Managers can afford to make mistakes but they cannot afford to lose trust. By practising behaviors that align with the core four elements that make up trust (demonstrate competence, act with integrity, care about others and maintain credibility) managers and leaders will not only set a healthy example but also inspire enthusiasm and success in those who follow them.

Ladd (2003) provides a different perspective that managers should pay attention to. He points out that deaf people are a sign language-using community that has been trying for over 250 years to build strong communities that will sustain them through the daily effort to co-exist alongside majority culture members who do not understand them. Yet throughout that time and 
despite all the setbacks, deaf people have continued to try and convince non-deaf people to learn sign language so that both communities can walk in and out of each other's worlds. Ladd considers that it is important that non-deaf people become bi-lingual adults so that these two communities will be able to interact collectively for the first time. It appears that sign language is a bona fide language and that the deaf culture per se is a bona fide culture. Bona fide in this context is defined as meaning 'used honestly and genuinely'. As deaf people cannot hear the intonation of voice, the words used and the associated body language, they rely solely on stand-alone body language, facial expressions and social interactions to make judgments whether to trust someone or not. It is perhaps less challenging for deaf people to express their distrust towards another person if this person is also a deaf person. In this respect, it is likely that the sign language acts in a similar way to normal phonetic language, as such acting as the equivalent aspects of sign. It is therefore possible for deaf people to communicate with each other and express their levels of trust between each other using sign language. This may also be supported by personal levels of experience as far as body language and some level of intuition are concerned. Behaviors are overt and usually non-verbal so this is another area where deaf as well as non-deaf people can make good use of the outcome of their observations in relation to building trust.

\subsection{Knowledge Gap}

The literature review from this current research suggests that trust is of paramount importance to managing people effectively at work. Building trust is a skill that, when applied appropriately, can help managers to achieve higher performance levels and challenging objectives within set performance targets such as Key Performance Indicators (KPIs). Some researchers argue that the benefits of building trust are not limited to individuals but that team dynamics can also be improved positively which in turn will lead to higher productivity levels. It appears that there is a widening gap between the performance levels companies expect their managers to achieve and the associated training and/or coaching that should accompany this change to ensure congruence. This research is about what the researchers perceive to be the nature of the resulting shortfall and what managers need to do to close this gap effectively. The outcome of the literature review has not been conclusive on its own to establish, for example, what the different levels of trust are or how to build long lasting trusting relationships at work. The outputs from the face to face interviews and the focus group meeting made some valid contributions to close this knowledge gap.

\subsection{Main Research Questions}

The main research questions for this research are:

1. What is meant by the concept of building trust?

2. Does a potential shortcoming exist between how managers need to build more trusting relationships now with their team members compared to how they used to do this in the past?

3. What are the traits, attitudes and behaviors of a manager who builds long term trusting relationships with his team? 
4. How can the contributions and outcomes from this research be applied practically by managers in the real business world?

\section{Research Methodology}

\subsection{Method}

The researchers applied a constructivist interpretivist research approach within a phenomenological research paradigm. This qualitative research approach was considered most appropriate as the researchers wanted to get close to the subject matter under investigation within what they consider to be a socially constructed world. Table 1 is a summary of the questions asked during the face to face and focus group meetings with the research participants. All answers were recorded in writing or recorded electronically where possible, with the full approval of the participants.

Twelve undergraduate and post graduate students were interviewed (70\% female, $30 \%$ male) between July and October 2014. Their age ranged from 22 to 26 years of age. Three students were post graduate students who were in full time employment at the time of the interviews and focus group meeting. All students had extensive part-time work experience and therefore brought valuable contemporary insights regarding building trust at work to this research.

Table 1. Research Questionnaire for the Face to Face Interviews

1. What is your definition of trust?

2. What does a trustful manager 'look like'? What are their attitudes and behaviors?

3. What skills do managers, for example, need to have and apply to build effective and long term working relationships?

4. Discuss how the approach to building trust may have changed over the years, giving some practical examples to support your views.

5. What is building trust dependent upon in any relationship, for example, between managers and subordinates or leaders and their followers? Is there something that must be in place before trust can start to develop?

6. How can the outcomes from this research be practically applied in working environments? Give some examples.

\subsection{Data Collection, Interpretation and Triangulation}

The researchers considered three methods to collect relevant research data to answer the main research questions from Section 1.4: a review of the literature (Section 1.2), face to face interviews (Section 3.1) and a focus group meeting (Section 3.2), within the context of a phenomenological research paradigm and an associated constructivist interpretivist research approach. All research data was triangulated and the results are summarized in Table 3, Section 4.

\section{Results}

\subsection{Face to Face Interviews}

What is your definition of trust? 'You rely on another person to keep confidential what you 
have told them and for this person to act with integrity. It is about another person being there for me when I need them, at any time. The other person needs to believe me or believe in me. This is a reciprocal approach' (Barbora, Pavel and Honza). 'It has something to do with the feelings that develop when talking to another person. These are feelings of comfort. It is also about being honest and open and the other person not misusing the information I share with them. It appears to me that there are higher levels of trust when I actively know the other person. The other person's social status is important. I trust an academic or professional business person much quicker than someone who has a lower social status. It's about non-verbal communications, too. Body language often tells the truth-it is not easy to lie by using body language. This helps to build good relationships' (Marketa, Petr and Svetlana). 'It's about sharing sensitive and personal information with another person and then not being stabbed in the back by this person. It is equally about being able to be sure that the other person will not misuse the shared information to their advantage. Active listening is the cornerstone of building trust and this requires mutual respect, too. We are all human beings. '(Nikol, Pavlina, Pavla). 'Trust is something that we cannot touch. It is a kind of chemistry between two people and makes us believe in what they say they are going to do. This develops over time. There are different levels of trust, ranging from trusting someone immediately to long-term trust which is based on personal experiences. We can assess the level by observing people's behaviors. It is also based on our perceptions as to why we should trust the other person' (Dominika, Peter and Pavla).

What does a trustful manager look like? What are their attitudes and behaviors? 'They change things ad hoc to suit the needs of the business and the people they work with. Their focus is on what is in the best interest of others. They put others first but without loss of sight of what is also important to the business and its customers. Trustful managers are open minded and listen actively to others. They give positive feedback and focus on the strength of abilities of others.

They praise people for work well done and are prepared to let others do their work with a minimum of supervision. Trustful managers give people independence so that these can grow as a person. They are available at all reasonable times to help, assist and support others. Team members are treated equally and there are no favourites. And finally, they will acknowledge openly the work others have done' (Nikol, Pavlina). 'You can spot a trustful manager very quickly. They do what they say they are going to do. Showing respect for others is one of their trademarks. They demonstrate a high level of knowledge about the job they do and act in accordance with their audience. They quickly adapt to changing priorities or business situations. They freely consult others for their views and opinions and they have learned to let go and not act as a control freak' (Dominika, Peter and Klara). 'A trustful manager is a person who will try to get closer to me by giving me the feeling that they are listening to what I am saying. They are also thinking about how to help me in the best possible way. They show empathy and share their thoughts/ideas/feelings openly with me. They appear to be connected with me. They imagine how I feel about things and then apply an approach that is appropriate to the situation I am in. They keep their personal agenda out and simply focus their attention on my needs and not theirs. The true value of a trustful manager is very much based on open and honest discussions without prejudice' (Honza). 
What skills to managers, for example, need to have and apply to build effective and long term working relationships? 'They need to respect everyone for what they stand for and are. They need to create a working environment that is built on openness and honesty. Behaviors need to be consistent so that people feel comfortable and safe. Treating everyone fair and in the same way is a good skill to have for a trustful manager. No favouritism. Trustful managers are good at operating a no-blame culture at work. They take full responsibility for problems and resolve these' (Dominika, Pavel). 'Soft skills are essential to become an effective people manager. This includes good communications. They deliver what they say they are going to deliver and put together teams that 'click'or 'gel', sometimes letting team members compete against each other to get the best out of the team' (Nikol, Pavlina and Petr). 'Effective and trustful people managers understand the differing characters and personalities of their team members such as introvert and extrovert. They align team roles with business goals and objectives and ensure that people with the right skills carry out the right jobs. They are passionate about what they do and this is clearly reflected in their behaviors and body language. They take their people with them and people are willing followers' (Barbora, Svetlana).

Discuss how the approach to building trust may have changed over the years, giving some practical examples to support your views. 'This is probably different from country to country and the prevailing cultural differences within these countries. Countries like the Czech Republic are probably very slow in this respect due to how we do business and how we interact with each other. A country like America is probably much faster when it comes to building trust. Basically, the core is the same but the environments have changed and how people feel about things. Foreign businesses, for example, in the Czech Republic, have already had a major influence on the approach people and businesses take to build trust. Typical companies are Tesco, Aldi, Lidl and H\&M. Improved, faster, and more efficient communication technologies also had a major impact on building trust.

Young people tend to trust others on the Internet (no threat) very quickly although services such as Skype are much better and safer for building trusting relationships' (Peter, Svetlana and Pavel). 'It looks like that everything has to be immediate nowadays. No one takes sufficient time any more to think first before offering trust. And because of this, there are fewer and fewer people who actually trust each other. People trust each other much more quickly nowadays' (Nikol, Pavlina and Pavla). 'The level of trust that used to be the case between people has changed dramatically. This is probably due to the fact that the system has changed. Relationships between people are not so deep anymore and certainly not so strong. Business also has changed. It is much faster and more driven by profit at the expense of caring much for people. Pressures at work, as a result, are much higher and this has had a negative impact on building effective work relationships that are built on trust' (Barbora, Klara).

What is building trust dependent upon in any relationship, for example, between managers and sub-ordinates or leaders and followers? Is there something that must be in place before trust can start to develop? 'It is important to connect with people first to understand, for example, how they communicate and what their personalities are. It is also good to know about people's strengths and weaknesses. It is important to make people feel special. Trust starts to develop when people begin to share some personal details' (Dominika, Peter and Honza). 'Having a 
good positive attitude towards other people is a must for developing strong and long lasting relationships with other people. There also appears to be a relationship between resolving problems and not trusting each other to resolve these. The level of trust depends on how well people know each other' (Nikol, Pavlina). 'Strong levels of trust are dependent on people spending more time together to get to know each other much better. When this is done properly, better and stronger trusting relationships will develop. It is equally important for mangers, for example, to get to know the personalities and characters better of those they wish to trust/trust more. The sharing of personal information will help people to make up their own minds of what the other person really is like and whether they can be trusted or not' (Barbora, Svetlana).

How can the outcomes from this research be practically applied in working environments? Give some examples. 'Managers need to lead more by example and this includes opening up more so that others follow their lead. This will lead to more trusting working relationships that will improve productivity, team morale and motivation levels. Managers only need to look at which buttons to press as far as family and friends are concerned and then apply the same principles at work. They should not push people any harder than they already do but back off a little bit and allow others to take more responsibilities based on trusting their manager more' (Dominika, Peter and Pavla). 'Managers should consider consultants to help when work loads are high and too much for existing people. This approach builds trust. People can see that the manager is actively trying to help them. This will go a long way. A manager must at all times display a positive attitude and demonstrate to others that the new way of working is the right way of working. It also helps if they can sell others to benefit of working differently' (Nikol, Pavlina and Petr). 'Managers need to think more about why building trust with others at work is so important.

They need to engage more with others in an open and honest way and then build strong trusting relationships that will last a long time. They need to give people more 'second chances' and should also trust some people blindly where the situation allows or calls for this type of approach. It is equally important to apply these approaches in work situations where the manager has no choice or input regarding who the team members will be. Building trust should also be included in school/college/university syllabuses to help young people develop this important life skill'(Svetlana and Dominika).

\subsection{Focus Group Meeting}

The focus group, made up of six of the twelve participants from the face to face interviews, met a week after the face to face interviews were conducted. The purpose of the focus group was to review the contributions the individuals made during the face to face interviews, in a group environment, and to check if the contributions from the face to face interviews could be improved and strengthened. This group provided further insights to answer the research questions from Section 1.4.

'Developing strong levels of trust can be achieved, by, for example, not talking behind people's backs. It is an essential ingredient of trust to be able to talk to managers openly and honestly without any concern or perhaps fear of any kind of retribution. It is imperative that managers 
today talk to their staff by treating them as human beings and not simply human resources. They also need to adopt a communications style that shows both partners as equals. Higher levels of trust can also be achieved by, for example, managers knowing the birthdays of all their staff. It shows that they really care' (Marketa). 'An effective trustful manager develops so-called pro-social behaviors. They will do things for the benefit of others and not exploit or misuse the trust others have in them. They will treat everyone the same and do not have any 'special people' in their teams' (Peter, Nikol and Barbora). 'A really trustful manager will show empathy openly and they are not afraid to do so. Honest applications of their creativity and intelligence with their teams will build much more effective working environments in future. They need to foster situations that make good team building and therefore trust building, possible. Constant and consistent team building itself leads to higher levels of trust between managers and their team members' (Pavlina, Dominika). 'It should be noted that the structure of societies has changed. This has a major impact on how people trust each other. This has probably something to do with the status people now have in their respective societies. Some people were trusted because of their societal status in the past. People nowadays are far more careful who they trust. They tend to analyse more who they can trust before they give their trust to others. They are far more critical. Trust has become much more important than it used to be due to societal changes. Mobile technology and social media have a major impact (Fisher, 2013) on how people now lead their lives. This includes how they trust people' (Marketa, Barbora). 'Trust can only be built if people want to build trust in the first place. Managers need to align people's goals as best as possible and develop an open-ness in people that they want to be open to co-operate more with others. They have to do this in such a way that people themselves want to do this. The results will be potentially higher levels of trust building between managers and their teams' (Dominika, peter and Nikol). 'Universities, and schools should adopt the outcomes of this research in their syllabuses, including the pro's and con's of building trust This would help young and inexperienced people to make informed decisions who they should share information with, involving personal details' (All).

\section{Discussion}

Human beings develop and build trust throughout their lives. From an early age, children, due to lack of practical knowledge and experience, observe the behavior of another person and if the behavior appears to be honest and accurate, they start to trust this person. Behavior is overt and they learn very quickly that this is a reliable means of finding out who they can trust and who not. By the time they have reached adulthood, and have started to work as a manager, for example, they understand that building relationships and rapport with others is of paramount importance if they want to achieve their work objectives. Trust is to building relationships what oil is to the engine of a car. If managers accept that trust is as important as the outcome of this research suggests, then they are on the right track to becoming better at managing others more effectively. But this does not happen by itself. Managers need to adopt a positive attitude towards trust building and accept that this will not be an easy task to complete. It requires personal sacrifices, taking of risks and higher tolerance levels as far as the attitudes and behaviors of others are concerned. Once managers have acquired this state of readiness, they need to show a genuine positive attitude towards everything they do and display associated 
authentic behaviors at all times, irrespective of the difficulty of situations they are in. There is no time for play acting as this is generally short lived and unprofessional. They must develop relationships with their team members that are based on openness, mutual respect and owning up to actions and create a work environment where people can make mistakes and learn from them. They must focus their attention on developing a no blame culture within their teams. This is conducive to building stronger levels of trust between people and leads to higher levels of effective working relationships. They must be seen to be taking ownership when things go wrong or have gone wrong. People will respond to this well by supporting their manager in finding ways of resolving the issues concerned. Trust acts as the catalyst for developing positive attitudes in others. They will start to believe in their abilities and capabilities much more and this will lead to higher levels of self-confidence. As a result, working relationships between the manager and team members will strengthen. Trust improves motivation levels in people and this will lead to higher levels of productivity. People are highly likely to show higher levels of willingness to do additional work without having to be asked. They will become more committed rather than being compliant because they have been told to do something. Commitment is long term and it is this kind of behavior managers need to achieve in people so that they can cope well with the ever-changing business demands placed upon them. Fig. 1 shows the relationship between trust, attitude/behaviors and confidence and increased performance/support.

\section{Trust}

\begin{tabular}{|c|c|c|}
\hline Trust & $\begin{array}{l}\text { Attitude and Behaviors } \\
\text { Confidence }\end{array}$ & $\begin{array}{l}\text { Increased Performance } \\
\text { Support }\end{array}$ \\
\hline $\begin{array}{l}1 \text { Strong } \\
2 \text { Genuine/Authentic } \\
3 \text { Based on Openness } \\
4 \text { Based on respect } \\
5 \text { Must be wanted } \\
6 \text { Must be truthful }\end{array}$ & $\begin{array}{l}1 \text { Acts as the catalyst } \\
\text { for developing positive } \\
\text { attitudes and behaviors } \\
\text { in people } \\
2 \text { Improves levels of } \\
\text { self-confidence due to } \\
\text { an increase in } \\
\text { self-belief } \\
3 \text { Forms the basis of } \\
\text { strong co-operative } \\
\text { working relationships }\end{array}$ & $\begin{array}{l}\text { 1Higher levels of } \\
\text { motivation } \\
2 \text { Higher productivity } \\
\text { levels } \\
3 \text { Improved open and } \\
\text { honest } \\
\text { communications } \\
4 \text { A stronger } \\
\text { willingness to support } \\
\text { and help others and } \\
\text { reducing 'silo'effects }\end{array}$ \\
\hline
\end{tabular}

Fig. 1. The Relationship between Trust, Attitude/Behavior and Increased Performance (Fisher, Bittnerova and Rupova, 2014)

Some work situations such as managing virtual teams or teams with members who cannot hear, require different approaches to building trust due to the prevailing circumstances. Managers who wish to increase trust levels within their virtual teams must ensure that the roles and responsibilities of team members are clear and unambiguous so that managers can trust people to get on with the job with a minimum of supervision and visibility of the actual work performed. There is less room for flexibility compared to work situations where managers have regular face to face contact with their teams. They need to talk to people over the phone using the right tone of voice. An aggressive or unassertive voice does not create high levels of 
confidence in others why they should trust the other person. They must show respect for the other person at all times so that mutual levels of respect can develop and establish themselves. These will strengthen over time. Managers must develop social knowledge amongst team members. For example, they need to know about the hobbies and likes and dislikes of individual team members and the things that are important to them. This will build a higher team spirit and higher levels of trust not only within the team but also between the manager and the team.

Managers who are working with team members who cannot hear must consider that these team members apply different ways of assessing how to trust another person. For example, they are using stand alone body language that is not supported by spoken words. Facial expressions of people are used to assess whether they can trust someone based on what they observe. There may also be elements of intuition or so-called gut feelings that may provide those who cannot hear with guidance as to who they can trust. Social interactions provide opportunities to observe other people's behaviors and the strength of the evidence from these observations may lead to conclusions whether to trust someone or not. Managers should make every effort to learn some basic sign language and to encourage all other team members to do the same. This will develop higher levels of mutual trust and respect between all team members and bring the spoken and the sign languages closer together for the mutual benefits of the speakers.

Different levels of trust require either a lot of time to develop or hardly any time at all. For example, it can take months for managers to develop a strong trusting relationship with a team member they see every day but people trust train drivers blindly to take them safely to their destination. Managers need to make the necessary time to invest in building trust with their teams as this will be the ultimate catalyst to improve team performance. Building trust is a two-way process that can reap enormous rewards for all parties involved when applied respectfully and considerately. This research has been limited to the Czech Republic and inputs from university students. Further investigations need to be conducted to establish how trust is built in diverse countries and how managers in these countries apply this at work. It would also be beneficial to engage practising managers in future research to gain new insights from a business perspective.

\section{Conclusions}

Building trust has many benefits for managers. It influences how decisions are being made, it reduces complexity and it allows for better coping with uncertainty. It deepens relationships through higher levels of creativity, quality and customer satisfaction. It helps to overcome barriers much more easily and increases productivity levels substantially. Managers who feel genuinely passionate about the work they do and the people they work with are more likely to build strong and long lasting relationships with individuals and teams. In return, team members will be committed to do things over the long term rather than being compliant which is short lived and highly undesirable. Managers who put others first and focus on their abilities can rely on the team members to 'go the extra mile' without the need to be asked to do so. It is this level of trust that is the difference between high and low performing teams. Managers who make others feel special create a strong foundation on which to build trust. They need to treat people 


\section{Macrothink}

Business and Economic Research

ISSN 2162-4860

2015, Vol. 5, No. 1

like human beings and not human resources. People will respond accordingly. A trustful manager displays pro-social behaviors that are commensurate with doing things for the benefit of others. This includes trusting others blindly when the situation demands it. The trust model (Fig.2) is a diagrammatical presentation of the eight competence and behavior areas the researchers identified and developed during this research. When applied by managers in accordance with prevailing corporate organizational and cultural differences, it is highly likely that managers will be able to meet the increasing business challenges and demands of businesses today and tomorrow. Trusting another person is probably one of the most valuable of gifts one person can give to another person.

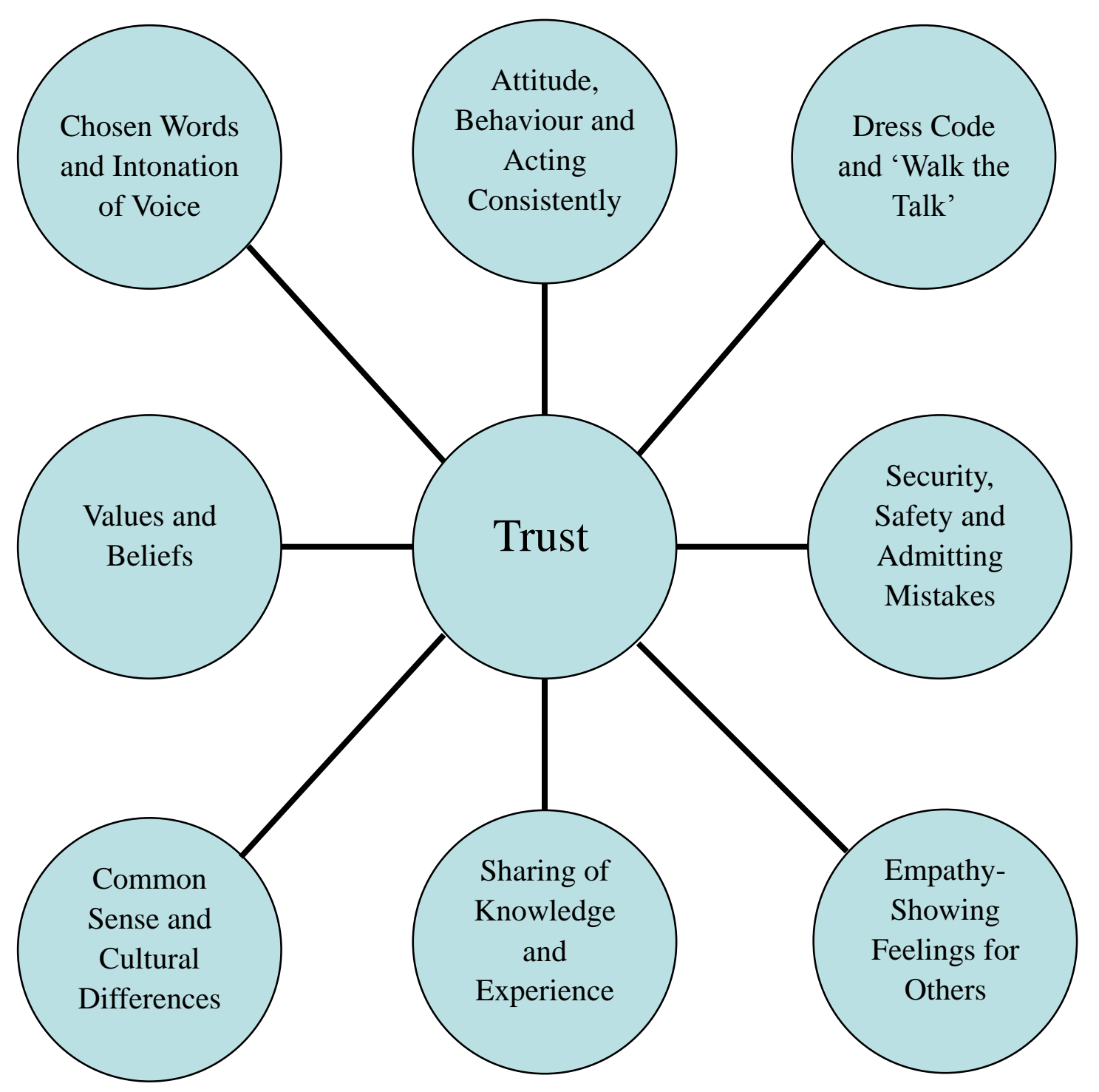

Fig. 2. The 'Eight of Trust' Model (Fisher, Bittnerova and Rupova , 2014)

\section{Acknowledgements}

The corresponding author wishes to thank the Palacky University in Olomouc, Czech Republic, for providing access to interview students from the Faculty of Psychology outside of formal teaching hours to assist with the completion of this research. 


\section{Macrothink}

Business and Economic Research ISSN 2162-4860 2015, Vol. 5, No. 1

\section{References}

Blanchard, K., Olmstead, C., \& Lawrence, M. (2013). Trust Works!-Four Keys To Building Lasting Relationships, Harper Collins Publishers

CMI SME (2013). Managing Others-The Organizational Essentials, The Checklist Series, Chartered Management Institute, pp. 169-174, Profile Books Ltd.

Covey, S. M. R. (2004-2006). The 13 Behaviors of a High Trust Leader, Covey Link, accessed at www.coveylink.com

Davison, S., \& Ward, K. (1999). Leading international teams, McGraw-Hill International

Fisher, E. (2013). From Cyber Bullying to Cyber Coping-The Misuse of Mobile Technology and Their Effects on People's Lives, Business and Economic Research, Macrothink Institute, 3(2), 1-19, http://dx.doi.org/10.5296/ber.v3i2.4176

Fox, A. (1974). Beyond Contract: Work, power and trust relations, Faber, London

Gabarro, J. J. (1990). The development of working relationships. In J. Gallagher, R. E. Kraut and C.Egido (Eds.). Intellectual teamwork: Social and technological foundations of cooperative work, pp. 79-110, Hillsdale, NJ: Lawrence Erlbaum Associates

Honey, P. (1997, 1988). Face to Face Skills, Gower Publishing

Hunsaker, P., \& Alessandra, T. (2008). The New Art of Managing People, Free Press, Simon \&Schuster, Inc.

Jones, A., Richard, B., Paul, D., Sloane, K., \&Peter, F. (2007). Effectiveness of team building in organizations, Journal of Management, 5(3), 35-37.

Ladd, P. (2003). Understanding Deaf Culture-In Search of Deafhood, Multilingual Matters Ltd.

O'Connor, J., \& Lages, A. (2007). How CoachingWorks-The Essential Guide to the History and Practice of Effective Coaching, A\&C Black

Piccinini, E. (2013). Behaviors that can develop and maintain trust in the Workplace, TMA

World.

Qing Gong, L., Heyman, G. D., Xu, F., \& Lee, K. (2014). Young children's use of honesty as a basis for selective trust, Journal of Experimental Child Psychology, 117, 59-72, Elsevier, http://dx.doi.org/10.1016/j.jecp.2013.09.002

Robbins, S. P. (2002). The Truth About Managing People and Nothing but the Truth, Prentice Hall PRT, Pearson Education, Inc.

Robbins, H., \& Finley, M. (1995). Why Teams Don't Work-what went wrong, and how to make it right, Peterson's/Pacesetter Books, Princeton, NJ 


\section{Macrothink}

Business and Economic Research ISSN 2162-4860 2015, Vol. 5, No. 1

Rousseau, D. M., Sitkin, S. B., Burt, R. S., \& Camerer, C. (1998). Not So Different After All: A Cross-Discipline View Of Trust, Academy of Management Review, 23(3), 393-404, http://dx.doi.org/10.5465/AMR.1998.926617

Sheppard, B. H., \& Sherman, D. M. (1998). The grammars of trust: A model and general implications, Academy of Management Review, 23(3), 422-437

Sprenger, R. K. (2004). Trust-The Best Way To Manage, Cyan/Campus

\section{Copyright Disclaimer}

Copyright for this article is retained by the author(s), with first publication rights granted to the journal.

This is an open-access article distributed under the terms and conditions of the Creative Commons Attribution license (http://creativecommons.org/licenses/by/3.0/). 